\title{
Repressão, adaptação, reinvenção: o download de música como lazer e negócio na internet (2006-2013) ${ }^{1}$
}

\section{Juliana de Alencar Viana}

Doutora; Centro Federal de Educação Tecnológica de Minas Gerais; Belo Horizonte, MG, Brasil juliana@cefetmg.br

\section{Rafael Fortes Soares}

Doutor; Universidade Federal do Estado do Rio de Janeiro; Rio de Janeiro, RJ, Brasil

raffortes@hotmail.com

\section{Resumo}

Este trabalho apresenta resultados de pesquisa que investigou como o download de música foi representado nas notícias do portal G1, entre os anos de 2006 e 2013. A pesquisa analisou 713 notícias com auxílio do programa Nvivo10. Observamos que houve um momento de repressão e perseguição aos usuários, fechamento de sites e redes de compartilhamento de arquivos por infringirem a Lei de Direitos Autorais; posteriormente houve uma adaptação da indústria, pela liberação de música digital gratuita em troca de receitas de publicidade baseadas em audiência. Por fim, houve uma reinvenção, por parte da indústria fonográfica, da música enquanto negócio, através da ampliação e diversificação dos canais de consumo, como assinatura de serviços online e games temáticos.

\section{Palavras-chave}

Download de música. G1. Notícia. Mídia. Criminalização.

\section{Introdução}

Em 2011, o Centro de Estudos sobre as Tecnologias da Informação e Comunicação (CETIC) destacou que, entre as atividades de lazer mais comuns na internet no Brasil, estava o download de música, realizado por $51 \%$ da população pesquisada, compreendendo as zonas urbana e rural, todas as regiões e diferentes faixas etárias (COMITÊ GESTOR DA INTERNET NO BRASIL, 2011). Reiterando esses dados, de acordo com um estudo de maio de

\footnotetext{
1 Este trabalho apresenta e desenvolve alguns resultados de tese Ascensão e queda: o download de música na internet nos discursos do portal G1 (2006-2013), defendida em 2016, no Programa de Pós-Graduação Interdisciplinar em Estudos do Lazer da Universidade Federal de Minas Gerais (VIANA, 2016).
} 
2012 do Instituto de Pesquisa Econômica Aplicada (IPEA), cerca de 81\% dos pesquisados (8,6 milhões de pessoas) consumiam músicas e filmes pela rede sem pagar (INSTITUTO DE PESQUISA ECONÔMICA APLICADA, 2012). Embora popular, a prática é condenada por muitos, que a classificam como "pirataria".

A Campanha Internacional contra a Pirataria, lançada no Rio de Janeiro pela Associação Brasileira de Produtores de Discos (ABPD), em 2006, foi um marco para a prática ser tratada como crime (LOUREIRO, 2006) ${ }^{2}$. 0 foco principal dessa campanha era a pirataria na internet (digital) e não a do CD, pois considerava-se que houvera uma migração do "delito" para a internet. Desde então, o download de música, entre outras práticas, parece ser considerado um mal da internet. Como consequência, enfatizou-se a regulação e normatização, visando ao combate de tal prática, tornando-a crime.

Observamos que iniciativas para criminalização do compartilhamento de arquivos de música têm se expandido nos EUA ${ }^{3}$ e avançam em outros países, ${ }^{4}$ como no Brasil. ${ }^{5}$ Neste, a norma em vigor é a Lei de Direitos Autorais (Lei no 9.610, de 19 de fevereiro de 1998), que não aborda o uso na internet, gerando interpretações conflitantes e dúvidas na aplicação da lei quando o assunto é download, troca ou compartilhamento de arquivos (BRASIL, 1998). Entre 2007 a 2010, houve alguns esforços pela reforma desta lei, sem sucesso. Já o pioneiro Marco Civil da Internet, aprovado em 2010, contém vários avanços e algumas fragilidades. Paganotti (2013) relata que, entre os pontos polêmicos tratados no Marco Civil - que justificaram atrasos em sua aprovação pela resistência de produtores culturais e de provedores de internet -, estavam o incentivo à produção e utilização de software livre nacional, a garantia da neutralidade na rede ${ }^{6}$ e a reforma das leis de direitos autorais. Para esse autor, apesar da iniciativa do Marco Civil na forma de consulta pública ter possibilitado vários avanços, o uso de plataformas colaborativas para outros projetos não conseguiu os mesmos resultados, como foi o caso do abandono do projeto de reformulação da lei

\footnotetext{
2 Em relação às referências bibliográficas das notícias em formato eletrônico utilizadas neste trabalho (corpus), note-se que poucas notícias têm autoria e a entrada, nesse caso, se deu pelo sobrenome do autor; a maior parte não tem autoria e a entrada na listagem foi feita pela primeira palavra do título da notícia. Para facilitar a localização dessas notícias na lista de referências, adotamos o padrão de inserir, no corpo do texto, a indicação do sobrenome do autor ou primeira(s) palavra(s) do título e indicação de ano.

${ }^{3}$ Sopa - Projeto de Lei de Combate à Pirataria On-line e Pipa - Protect IP Act (EUA). Ver também notícias citadas na seção 2.

${ }^{4}$ No plano internacional, houve punições para o programa de compartilhamento Napster e o site The Pirate Bay, bem como iniciativas de legislação punitiva: Lei Hadopi (França); Acta - Acordo Comercial Anticontrafação, um tratado comercial internacional entre diversos países (SOARES, 2012); Lei Sinde (Espanha).

5 Uma tentativa importante de legislar sobre o assunto foi o Projeto de Lei do senador Eduardo Azeredo (PL 84/99), que visava incluir cibercrimes no Código Penal brasileiro e recebeu críticas por seu caráter punitivo, entre outros aspectos.

${ }^{6}$ No extremo oposto, encontra-se a restrição ao acesso dos usuários a determinados dados ou serviços pelas operadoras e provedores de internet.
} 
brasileira de direitos autorais. Entretanto, o assunto direito autoral não deixou de ser tratado no Congresso, pelo menos não sob a forma de consulta, com participação pública. Moraes (2010) afirmou que existiam, pelo menos, quarenta e três projetos de lei tramitando no Congresso sobre a regulamentação da internet?

Tendo em vista esses dados, consideramos que estão em curso mecanismos de controle sobre as práticas de lazer na internet, sendo elas lícitas ou ilícitas, permitidas ou proibidas, conforme os interesses de determinados grupos, convertendo-as em objeto de disputa cultural.

Houve um destaque inédito na imprensa brasileira nesse período mencionado. A prática social do download de música na rede aponta para diversos usos e interesses, sejam eles econômicos, políticos ou culturais, e sugerem possíveis assimetrias no exercício e nas relações de poder. Parece oportuno discutir esses elementos nas representações midiáticas, considerando que a mídia é responsável pela constituição de mundo, dada a veiculação de formas simbólicas cruciais para a cultura contemporânea, contribuindo para a naturalização de crenças a fim de estabelecer ou sustentar relações de poder. Consideramos que o uso da linguagem é ideológico se servir para instaurar ou manter assimetrias entre pessoas e grupos sociais (THOMPSON, 1995).

Dado o exposto, interessa-nos discutir: como o download de música foi representado na mídia? 0 objetivo deste trabalho é analisar representações midiáticas acerca do download de música na internet entre 2006 e 2013, período que compreende iniciativas tanto para o cerceamento da prática quanto para o debate público a seu respeito.

Adotamos como marco inicial a Campanha Internacional contra a Pirataria, de outubro de 2006, quando houve uma significativa mudança de foco da pirataria física dos CDs vendidos por camelôs para a pirataria digital e, como marco final, o III Plano Nacional de Combate à Pirataria, lançado em 14 de maio de 2013, ação governamental diretamente relacionada ao tema, principalmente no sentido de inibir o que se considera pirataria digital. Esse recorte temporal se justifica na medida em que observamos que o período implicou em maior controle e monitoramento do download de música na internet. A partir disso, nos pareceu interessante investigar e analisar os discursos midiáticos acerca do download de música como prática contemporânea de lazer, já que os discursos, enquanto prática social, manifestam e produzem os significados e sujeitos, revelando diferentes interesses -

\footnotetext{
${ }^{7}$ Uma lista de Projetos de Lei na Câmara sobre o controle à internet foi realizada por Rodrigo Veleda, do blog Não sou um número (VELEDA, 2009).
} 
políticos, econômicos, culturais e ideológicos. Reconhecemos a relevância do jornalismo não só na projeção dos assuntos na sociedade, mas também no enquadramento desses assuntos ao servirem como fontes de informação e de formação da opinião pública, moldando percepções da realidade.

Para discutir as questões propostas, inicialmente buscamos notícias do portal Globo.com sobre o tema. Segundo o Alexa, o portal é o $6^{0}$ site mais acessado do Brasil, o que o tornou - e torna - um importante veículo midiático ${ }^{8}$. Além disso, o portal pertence às Organizações Globo, o maior grupo de comunicação do país e da América Latina, que atua em diferentes segmentos, inclusive na indústria fonográfica ${ }^{9}$. Essa foi uma escolha ciente de que não há neutralidade na produção e veiculação de discursos por parte das empresas de comunicação.

Em agosto de 2013, foi feita uma busca com as palavras-chave download, música; baixar ${ }^{10}$, música. Encontramos 3.241 resultados para download e música e 2.485 resultados para baixar e música, entre notícias, fotos, vídeos e áudios. Desses resultados, percebemos que o tipo notícias agregou o maior número de resultados (3.233 dos resultados para download e música e 2.480 para baixar e música).

Dos cinco primeiros veículos em que mais notícias foram encontradas, em ambas as buscas, ${ }^{11}$ apenas G1 e $O$ Globo compreenderam todo o recorte temporal. Em função da quantidade de dados, da incidência do tema e das características dos veículos ${ }^{12}$, optamos pelo G1. De acordo com os princípios editoriais das Organizações Globo, “[...] cada veículo tem um público-alvo e deve agir de acordo com as características dele, adaptando a eles pauta, linguagem e formato." (ORGANIZAÇÕES GLOBO, 2011, p. 19). Logo, o tema parece ter como um importante público-alvo os internautas, que também são interagentes com a prática do download, sendo mais um motivo para a escolha. Considerando o foco no G1 e o marco temporal, chegamos às 713 entradas que foram analisadas.

\footnotetext{
${ }^{8}$ Alexa Internet Inc. é um serviço de internet pertencente à Amazon (empresa multinacional de comércio eletrônico) que mede quantos usuários de internet visitam um sítio da web (ALEXA, 2018).

9 As Organizações Globo são proprietárias da gravadora Som Livre. Criada em 1971, a Som Livre destacou-se no mercado brasileiro de discos, de início, produzindo trilhas sonoras de novelas e coletâneas com sucessos nacionais e internacionais (BRITTOS; BOLAÑO, 2005). Por meio da SLAP, Som Livre Apresenta, produz novos artistas e atua no comércio eletrônico de música (loja virtual) e rádio online. Atualmente, a gravadora integra a Pró-Música Brasil Produtores Fonográficos Associados e que, por sua vez, está vinculada à Federação Internacional da Indústria Fonográfica, IFPI (PRO-MÚSICA BRASIL, c2018).

100 termo em inglês download, já popularizado no Brasil, também é traduzido e utilizado como o verbo baixar. No país, fazer download de música ou baixar música possuem o mesmo significado, por isso a inclusão na busca.

11 Os cinco primeiros com as palavras-chave baixar e música foram: Letras, TechTudo, O Globo, G1 e Extra Online. Com as palavras-chave download e música: G1, TechTudo, O Globo, Letras, e Extra Online.

12 De acordo com Souza et al. (2013), o critério de atualidade é muito mais forte no veículo online, que publica um número de notícias bastante superior ao dos veículos impressos.
} 
O programa de computador de análise qualitativa de dados NVivo10 foi utilizado para facilitar a organização e recuperação do material empírico em função das categorias de análise. Para este trabalho, optamos por destacar algumas discussões relativas aos aspectos políticos e econômicos, reorganizadas a partir de três tópicos: repressão, adaptação e reinvenção.

Investigar os discursos sobre o download de música como fenômeno cultural pode ajudar a compreender as tentativas de controle e as subversões em torno dos significados da cultura do consumo musical. A produção dessas dicotomias, entre o que é lícito e o que é ilícito, é cercada de controvérsias que buscamos discutir.

\title{
2 Repressão
}

A Campanha Internacional contra a Pirataria foi lançada em 16 países por entidades vinculadas à Federação Internacional da Indústria Fonográfica (IFPI na sigla em inglês), que representa os interesses de 1.300 gravadoras em 60 países (INTERNATIONAL FEDERATION..., 2018) e atua no combate à violação dos direitos autorais, incluindo o combate à pirataria. A iniciativa foi apresentada da seguinte forma:

\begin{abstract}
A Associação Brasileira de Produtores de Disco (ABPD) começa nesta terça-feira (17) uma campanha educativa para alertar sobre os riscos do crime de pirataria. [...] Baixar música pela internet é crime previsto pelo Código Penal e pelo Código Civil. Dependendo da gravidade do caso, o infrator pode ser punido com pena de reclusão por violação de direito autoral e, ainda, pagar multa. No Brasil, no entanto, ainda há poucas pessoas sendo punidas pelo crime. 0 principal foco da campanha, no entanto, não é punir o usuário eventual, mas sim aqueles que fazem uso frequente da pirataria (LOUREIRO, 2006, doc. não paginado).
\end{abstract}

A campanha buscou alertar sobre os riscos de baixar música pela internet, o que configuraria o crime de pirataria, cuja pena incluía reclusão e multa. Embora aponte que o foco da campanha seriam os usuários "que fazem uso frequente da pirataria", não se estabeleceu que parâmetro os distinguiria dos demais. 0 texto é taxativo ao classificar o download como crime (discutiremos este assunto adiante) e ao considerar raras as punições.

O foco da campanha coincide, segundo a notícia, com a queda da comercialização ilegal de CDs piratas devido à ação do governo federal e ao número significativo de 
downloads "ilegais" no país. De acordo com outra notícia, mais de um bilhão de arquivos foram baixados ilegalmente no país em 2005 (EM 2005..., 2006).

Ações sistematizadas vinham ocorrendo desde a criação de uma Comissão Parlamentar de Inquérito, a CPI da Pirataria, em maio de $2003^{13}$ (BRASIL, 2004). 0 principal resultado da comissão fora a criação do Conselho Nacional de Combate à Pirataria (CNCP), “órgão público de inteligência" para articular e implantar políticas públicas sobre a questão (BRASIL, 2017).

Após o lançamento da Campanha, identificamos uma série de notícias sobre operações da Polícia Federal "para combater pirataria na internet" através de apreensões e buscas, que poderiam resultar em "prisões em flagrante" (PF REALIZA..., 2008), caso se verificasse que o material localizado fosse destinado à comercialização ilegal, como sugere o trecho a seguir:

Os detidos em flagrante tinham mídias para distribuição de conteúdo pirata ou disponibilizavam essas informações contidas em seus computadores via download na internet. Entre o conteúdo comercializado ilegalmente pelos investigados estão aplicativos, games, músicas, filmes e seriados. Eles responderão pelo delito de violação de direito autoral, além do crime previsto na lei de proteção a direitos autorais de software. Nos dois casos, a pena máxima é de quatro anos de reclusão. (CARPANEZ, 2008, doc. não paginado).

A notícia menciona o comércio ilegal e garante haver respaldo para a criminalização em duas leis. Entretanto, como identificar que os arquivos contidos em um computador eram destinados ao comércio ilegal? A notícia não esclarece. Fica a dúvida se manter arquivos no disco rígido do computador tornaria qualquer usuário um potencial criminoso, o que carece de ponderação, pois a própria Lei de Direitos Autorais (BRASIL, 1998) traz limitações nos direitos autorais, como veremos a seguir.

Concordamos com Moraes (2010) ${ }^{14}$ que, apesar de imprecisa, a definição da pirataria por parte da indústria cultural (IC) não remete necessariamente ao lucro do pirata, mas à ausência de retorno financeiro para si ${ }^{15}$. Para a IC, a característica fundamental da

\footnotetext{
${ }^{13}$ A CPI da Pirataria, com atividades entre junho de 2003 e junho de 2004, teve como finalidade investigar fatos relacionados à pirataria de produtos e serviços industrializados (bebidas, cigarros, livros, CDs, softwares, produtos farmacêuticos, óculos, peças automotivas, TV por assinatura etc.) e à sonegação fiscal. A CPI compreendeu a pirataria como "[...] toda espécie de adulteração e falsificação de produtos, promovendo com isto incalculáveis prejuízos ao consumidor e estupendo desvio de impostos que poderiam ser revertidos em serviços públicos visando ao bem-estar da população brasileira." (BRASIL, 2004, p. 9).

${ }^{14}$ A obra de Moraes (2010) é uma sólida contribuição ao debate acerca da pirataria no ciberespaço.

${ }^{15}$ Indústria cultural no sentido definido por Adorno e Horkheimer (1985).
} 
pirataria é ser um complicador para o modelo de negócio em que os produtos culturais são reconhecidos como objetos dotados de valor de mercado. E, como é característico do capitalismo, a submissão ao mercado deve ser não uma escolha, mas um imperativo (WOOD, 2001).

0 termo pirataria, enquanto crime, não está presente no Código Penal, no Código Civil ou na Lei de Direitos Autorais. 0 que consta no primeiro é a violação ao direito autoral, em especial, no artigo 184 (BRASIL, 2003). Já o artigo 927 do Código Civil estabelece a responsabilidade civil e a obrigação de indenizar (BRASIL, 2002). Na Lei de Direito Autoral, o termo técnico que merece destaque para esta discussão é contrafação, conceituado como "reprodução não autorizada", mas que não é tratado para além da mera definição. Vale ressaltar que, embora ela proteja os direitos autorais, elenca algumas limitações:

Art. 46. Não constitui ofensa aos direitos autorais: I - a reprodução: [...] VI a representação teatral e a execução musical, quando realizadas no recesso familiar ou, para fins exclusivamente didáticos, nos estabelecimentos de ensino, não havendo em qualquer caso intuito de lucro [...]. (BRASIL, 1998).

Contudo, Lemos (2005) observa que certas violações a direitos autorais passaram a ser criminalizadas, especialmente aquelas relativas à violação dos "direitos conexos"16, em função dos avanços tecnológicos. Segundo ele, a Lei no 10.695, de 1o de julho de 2003, modificou o artigo 184 do Código Penal brasileiro, que visa "[...] criminalizar não só as violações ao direito do autor, como dispunha o Código Penal antes da alteração ${ }^{17}$, mas agora também as violações aos direitos conexos, de produtores, intérpretes e executantes." (LEMOS, 2005, p. 160). 0 autor observa ainda que o direito brasileiro, apesar de tentar considerar o equilíbrio de interesses entre propriedade intelectual e o direito à informação, acabou por "[...] gerar uma série de imprecisões que podem afetar a inovação tecnológica no país, bem como a repressão a atividades legítimas, por causa da ausência de segurança jurídica derivada da falta de clareza do texto legal." (LEMOS, 2005, p. 160).

\footnotetext{
16 Segundo o autor, a expressão "direitos conexos” é empregada em tratados internacionais dos quais o Brasil é signatário e corresponde ao direito de artistas, intérpretes, executantes, produtores, organismos de radiodifusão e outros, derivados originariamente do direito autoral. O Convênio de Roma e a Convenção para a Proteção aos Produtores de Fonogramas contra a Reprodução não Autorizada de seus Fonogramas, realizada em 1971, em Genebra, ambas assinadas pelo Brasil, tratam desses direitos conexos (LEMOS, 2005).

17 Importante destacar que a alteração no Código Penal coincide com o período de realização da CPI da Pirataria (30 de maio de 2003 a 09 de junho de 2004). Uma de suas recomendações era a alteração do Artigo 184 do Código Penal. Alteração essa realizada antes mesmo do fim das apurações da CPI. A Lei no 10.695, que altera e acresce ao Art. 184, data de 10 de julho de 2003 (BRASIL, 2003).
} 
Segundo o autor, o que tem sido bastante debatido no Brasil, é se a mera troca de arquivos pela internet configuraria a hipótese de lucro direto ou indireto, ainda que dela não seja derivado nenhum ganho financeiro. Nessa disputa, então, milhões de usuários no Brasil poderiam estar cometendo a infração penal descrita, segundo interpretação da lei. Assim, a interpretação razoável é de que lucro corresponde ao resultado da atividade do empresário, que organiza os fatores de produção, obtendo ganho que supera o investimento realizado. "Ele é direto quando auferido pelo próprio empresário e indireto quando beneficia outrem. Em ambos os casos, o compartilhamento de arquivos em redes peer to peer não se inclui." (LEMOS, 2005, p. 164).

Ainda assim, boa parte das insinuações de violação ao direito autoral negligenciam a existência, na Lei de Direitos Autorais (BRASIL, 1998), de limites que conferem legalidade a práticas como o uso privado pelo copista. Trata-se de terreno em disputa. Para Machado, (2010, p. 37) “[...] a necessidade de legalidade e de aceitação serena de uma tecnologia altamente favorável ao desenvolvimento social e econômico nos obriga a mudar de paradigma." 18.

Contudo, os distintos usos da cultura tenderam a ser homogeneizados pelo discurso da indústria apontando para a possível penalização dos envolvidos, educando para a troca comercial (compra de música) e menos para outras formas de interação, como a partilha gratuita e solidária em rede.

Processos e prisões se sucederam pelo mundo e foram amplamente divulgados pelo G1:

Mais uma notícia de condenação: Um homem acusado de disponibilizar e permitir o download, a partir de seu blog, de nove canções inéditas da banda Guns'n'Roses foi detido em sua casa, em Culver City (Califórnia, Estados Unidos), sob a suspeita de infringir as leis federais de propriedade intelectual. (INTERNAUTA..., 2008, doc. não paginado).

A notícia endossa algo já dito: a indistinção entre os usuários que fazem uso avançado ou moderado das redes de compartilhamento, bem como o silenciamento em torno do direito de privacidade e segurança na web.

\footnotetext{
18 Alguns exemplos de pesquisadores e ativistas que defendem a necessidade de reformulação das leis: Wachowicz (2011); Wachowicz e Santos (2010); Observatório da Privacidade e Vigilância do Grupo de Pesquisa em Políticas Públicas para o Acesso à Informação da Universidade de São Paulo (GPOPAI-USP), que monitora ações do Estado e de empresas que tenham impacto sobre a privacidade dos cidadãos (CARTA CAPITAL, 2016).
} 
Outras ações reforçaram o "marketing do medo" (GRAVADORAS..., 2009). Ao enfocar distintos atributos pessoais dos sujeitos, como "mãe solteira", "garoto", "velhinha", as notícias sugerem que não há distinção de gênero, idade ou grupo social para quem pratica tais atos "ilícitos" e que todos podem ser igualmente punidos:

Uma mãe solteira com quatro filhos foi condenada nos Estados Unidos a pagar 1,5 milhão de dólares por ter baixado ilegalmente 24 músicas [...]. (EUA..., 2010, grifo nosso, doc. não paginado).

"Ela chorou, ficou devastada", afirmou o advogado [...]. "Ela é uma mulher que depende muito de seu salário" [...]. (DOWNLOAD..., 2007, grifo nosso, doc. não paginado).

Um aluno universitário, condenado a pagar US\$ 675 mil às gravadoras por baixar e compartilhar músicas ilegalmente, terá também de destruir todos os arquivos de música que deram origem ao processo [...]. (EUA..., 2009, grifo nosso, doc. não paginado).

Para seu advogado, [...] Tenenbaum é "um garoto que fez o que os garotos fazem" e não deve ser penalizado severamente [...] (ESTUDANTE..., 2009, grifo nosso, doc. não paginado).

Avó é multada em US $\$ 650$ por baixar 3.000 canções na internet. A idosa, de 66 anos, saiu chorando do tribunal que a condenou. 0 caso foi julgado na cidade de Montauban, na França. [...] A velhinha [...]. (AVÓ..., 2007, grifo nosso, doc. não paginado).

Cruz (2008) afirma que os processos judiciais, nesses casos, identificam os suspeitos de compartilhar arquivos pelo IP19 atribuído a eles pelos provedores de serviço de internet. Segundo Selaimen (2010), os provedores de acesso são nodos tecnológicos fundamentais para a garantia ou violação dos direitos dos usuários, sobretudo quanto à privacidade e à liberdade de expressão. Segundo Vidal (2010), os conceitos unitários de privacidade podem albergar-se dentro de quatro principais categorias: o direito de estar só, o resguardo contra interferências alheias, o segredo ou sigilo e o controle sobre informações pessoais. Para o autor, o interesse por informações pessoais é, atualmente, o principal elemento que leva à erosão e desvalorização do direito à privacidade.

Além da perseguição aos usuários considerados "piratas", a indústria também processou, condenou e encerrou atividades de sites (como Megaupload) e programas de

\footnotetext{
19 IP é a sigla para Internet Protocol, Protocolo de Internet, em tradução livre. Em uma definição simplificada, podemos dizer que é um número único que identifica dispositivos (computador, roteador, impressora etc.) na rede e é o meio pelo qual esses dispositivos se comunicam e trocam informações.
} 
compartilhamento (como The Pirate Bay e Limewire) (GOVERNO..., 2012; JUIZ..., 2010; JUSTIÇA..., 2009).

No Brasil, o programa K-lite Nitro se insere nesse contexto de perseguição a sites e programas de compartilhamento de arquivos. Seu criador foi um dos raros acusados a ter espaço para se manifestar nas matérias - quando isto ocorria, geralmente era por meio de pequenas falas dos advogados de defesa, como nas passagens citadas acima.

Réu no processo movido pela Apdif [Associação Protetora dos Direitos Intelectuais Fonográficos], Luciano Cadari se defende [...] dizendo que [...] em momento algum fez propaganda em favor da pirataria. "Nossa ferramenta é usada para compartilhar arquivos. Nunca induzimos ninguém a baixar conteúdo ilegal. Pelo contrário, sempre deixamos claro, com avisos para que os internautas não utilizem o software para fins de pirataria", afirmou ao G1. "Me pegaram para Cristo para fazer o marketing do medo". [...] Segundo Cadari, o software K-Lite Nitro [...] não tem o objetivo de infringir direitos autorais, apesar da "potencialidade" de download ilegal. "É como uma faca, que tem a potencialidade de matar. Um carro também tem a potencialidade de matar, em acidentes de trânsito. Por que não são proibidos também?", questiona. [...] "Estão colocando a culpa da queda nas vendas da indústria fonográfica em uma empresa de fundo de quintal de Curitiba", disse Cadari, cuja empresa tem quatro funcionários. "A guerra não é só contra mim; é contra todos os internautas brasileiros, contra a liberdade de expressão" (GRAVADORAS..., 2009, doc. não paginado).

Observamos que, quando as notícias dão algum espaço para posicionamento dos acusados, amplia-se a variedade de pontos de vista, favorecendo o debate. Por exemplo, a liberdade de expressão aparece na fala do microempresário. Contudo, as notícias citadas têm em comum a ausência da discussão sobre o assunto, um dos direitos e garantias fundamentais presentes na nossa Constituição. A repressão, contudo, não foi a única estratégia da indústria fonográfica para lidar com o download.

\section{Adaptação}

A indústria fonográfica buscou também "abraçar a internet", visando a novas possibilidades de faturamento no contexto digital, diversificando seus canais de oferta de consumo musical (HOLTON, 2009). Entre as inovações, encontramos a venda de bens materiais (como vinis ou CDs apresentados como itens raros ou artigos de colecionador) acompanhados da oferta "gratuita" do download digital das mesmas faixas (CANTOR..., 2009). 
No que se refere à venda de discos, de acordo com Vanessa Kikko, nos últimos anos, temos visto um ressurgimento do vinil também no Brasil: "Esse movimento apela mais para o colecionador, mas a cada dia tem conquistado o ouvinte amador, que gosta da boa música, com uma boa qualidade de som, e que tem feito dessa atividade um hobby." (KIKKO, 2012, p. 44). Para a autora, além da nostalgia e do valor simbólico da capa do disco, o que motiva a compra é a melhor qualidade do som. Para os especialistas, a agulha que toca o disco produz um som melhor do que a tecnologia a laser. Em um mercado de massa, às vezes saturado pela exaustão das novidades, o mercado de nicho, com um público consumidor especializado, cresce: "E os consumidores exigem cada vez mais opções. A era do tamanho único está chegando ao fim e em seu lugar está surgindo algo novo, o mercado de variedades." (ANDERSON, 2006, p. 7). De acordo com o IFPI (INTERNATIONAL FEDERATION..., 2015), isso sublinha o empenho da indústria em favorecer a escolha do consumidor ao oferecer música aos fãs no maior número possível de formatos, reforçando a ideia do mercado por nichos, conforme sugere Anderson (2006). Apesar de o autor tratar dessa questão em ambiente digital, também podemos pensá-la para a reinvenção de outros formatos (raridades, itens para colecionador, itens exclusivos, tiragens limitadas etc.), incluindo os formatos físicos. Dessa forma, apesar da emergência do digital e com a emergência do digital, a indústria aprendeu a diversificar os seus negócios, já que, segundo Anderson (2006), encontra-se consumidor para todo o tipo de bem e serviço, em maior ou menor proporção.

Em relação às ofertas gratuitas de faixas digitais (CANTOR..., 2009), como citado, o download grátis ofertado quando da compra de um vinil não ficou apenas relacionado à compra de um bem material, como CD ou vinil. Arquivos foram disponibilizados em sites de grande audiência:

A multinacional fonográfica EMI decidiu se unir ao Baidu, o portal mais popular da China, para oferecer música gratuita de artistas locais em troca da divisão dos lucros e de espaço publicitário [...]. O Baidu é o quarto portal mais visitado do planeta e os downloads de música em formato MP3 representam $14 \%$ do tráfego de dados do site. [...] As vendas de espaços publicitários em portais de busca da China cresceram quase $50 \%$ em 2006 , a 157 milhões de iuanes (cerca de US\$ 20 milhões), com um ritmo de expansão comercial muito maior que o de outros sites chineses. Entre os portais de busca pela internet, o Baidu controlou no ano passado $39 \%$ do mercado chinês de publicidade, seguido pelo Google, com 20\% [...] (EMI..., 2007, doc. não paginado). 
De acordo com o próprio G1, “[...] o Baidu.com liderou o mercado no quarto trimestre [de 2007] com uma parcela de 60,1\%, afirma a Analysis International, enquanto o Google ficou em segundo com 25,9\% [...]." (GOOGLE..., 2008b, doc. não paginado). Além de país mais populoso do mundo, a China também tem o maior número de usuários de internet, ${ }^{20}$ dados que evidenciam um grande mercado consumidor potencial para empresas que atuam com a oferta de bens e serviços digitais.

Somam-se neste território iniciativas do Google, como o lançamento de um serviço de download gratuito exclusivo para o país:

O Google escolheu a China para lançar seu primeiro serviço de download legal e gratuito de música, informou hoje o jornal "Shanghai Daily". [...] 0 Google informou que lançará o serviço através do site chinês "Top100.cn", que até agora oferecia downloads pagos. O serviço será financiado com publicidade e o lucro será dividido entre Google e "Top100.cn" [...]. Esta nova utilidade do Google faz parte da estratégia da companhia de aumentar sua presença na China e de alcançar seu maior concorrente [...], o buscador "Baidu.com" (GOOGLE..., 2008a, doc. não paginado).

A notícia evidencia um esforço do Google em busca da atenção do consumidor da esfera digital no território chinês, onde precisa concorrer com o Baidu. Tal propósito é reiterado pelo estabelecimento de funcionalidades específicas:

A versão chinesa do site de buscas Google lançou hoje, apenas para o país asiático, um serviço de download gratuito de músicas centrado especialmente em música chinesa, mas que também disponibiliza temas em outros idiomas. 0 novo serviço permite ouvir cerca de 350 mil músicas via web ou baixá-las no computador e, por enquanto, só estará disponível na China [...]. O serviço de download se assemelha ao oferecido pelo Baidu.com, o site de buscas mais popular entre os internautas chineses, com mais de $60 \%$ da fração de mercado (o dobro do Google), algo que os analistas atribuíam justamente ao fato de o primeiro oferecer música [...] (GOOGLE..., 2009, doc. não paginado).

A versão chinesa do Google visava a atrair, por meio do acesso gratuito ao conteúdo musical, uma das maiores audiências do mundo.

0 que se observa nas notícias anteriores, que tratam do interesse da audiência por sites que ofereceram download gratuito de música, é um novo modelo de receitas de publicidade (anúncios online) baseado em audiência, intitulado flot. Nele, quanto maior o fluxo de usuários, mais valorizado torna-se o espaço de veiculação publicitária. Esse modelo

\footnotetext{
${ }^{20}$ Em 2013 eram 618 milhões de usuários de internet ativos (INTERNATIONAL FEDERATION..., 2014).
} 
parece ter sido inaugurado pelas plataformas de compartilhamento gratuito de música e apropriado pelas gravadoras e corporações digitais, que nele identificaram novas potencialidades econômicas.

A extensão da propaganda ao ambiente online criou várias novas formas de anúncios além do modelo tradicional [...], que precifica o pagamento por milhares de espectadores ou ouvintes, conhecido como "custo por mil" (CPM). As variantes online incluem o "custo por clique" (CPC), que o Google utiliza, e o "custo por transação" (CPT), no qual os anunciantes só pagam quando a pessoa se torna um cliente pagante, como o programa Associates, da Amazon. Também temos a "identificação de clientes potenciais", em que os anunciantes pagam pelos nomes e endereços de e-mail de pessoas que foram atraídas ao conteúdo grátis ou pelas informações sobre esses consumidores. Os anunciantes podem patrocinar todo um site ou departamento por um valor fixo, não determinado pelo tráfego. (ANDERSON, 200921 apud LIMA, 2013, p. 97).

Segundo Lima (2013), as empresas que atuam em torno da música digital também investem no estabelecimento de redes de usuários que permitem o acesso aos dados de suas preferências e hábitos de consumo, obtidos por meio de cadastros e construções de perfis. Esses dados também se convertem em fontes de receita na economia em rede, pois se transformam em elementos para fidelizar audiência e manter o interesse dos anunciantes. Ademais, como afirma Patel (2010), a gratuidade de um bem ou serviço busca alterar as preferências do consumidor enquanto uma aposta, ou seja, enquanto possibilidade continuamente renovada.

Outro serviço noticiado que incluiu canções "grátis" foi o site Qtrax:

\begin{abstract}
Após passar uma década tentando combater a pirataria de músicas pela internet, parte da indústria fonográfica decidiu liberar, a partir desta segunda-feira, o acesso gratuito a mais de 25 milhões de canções pela internet. 0 serviço de música online Qtrax anunciou, neste domingo, uma parceria com grandes gravadoras, incluindo EMI, Sony BMG, Universal Music e Warner Music, que vai possibilitar que usuários baixem de graça títulos dos mais variados gêneros, desde grandes hits da atualidade até clássicos e raridades. [...] Como parte do acordo, artistas e gravadoras serão pagos conforme o número de acessos às suas músicas e ainda receberão uma fatia do que for arrecadado com os anúncios publicitários feitos na página da Qtrax. Empresas como Microsoft, Mc Donald's e Ford já revelaram que serão alguns dos anunciantes (SITE..., 2008, doc. não paginado).
\end{abstract}

${ }^{21}$ ANDERSO N, Chris. Free: grátis: o futuro dos preços. Rio de Janeiro: Elsevier, 2009. Apud Lima, 2013. 
0 trecho evidencia a abertura de uma nova frente pela indústria fonográfica, o que de forma alguma significou o abandono da lógica repressiva: parte da estratégia de adaptação consistiu no estabelecimento de sites e serviços legais/autorizados para download de música, consequentemente mantendo ou jogando os demais na ilegalidade.

Não obstante, dentro do universo da música surgiram alternativas ao flot como modelo de negócios. Isto se deu por meio da ampliação dos serviços de assinatura de música online e pelo crescimento nas vendas de games musicais, como veremos a seguir.

\section{Reinvenção}

Houve um discurso bastante favorável, mesmo que indireto, 22 à questão da obsolescência tecnológica como fator de promoção de novos serviços digitais, como a escuta de música online - que exige condições favoráveis de banda larga, fato muitas vezes omitido pelo G1 - e, não mais dependente de download para armazenamento em disco no computador (HD), assim como a promoção de dispositivos portáteis em detrimento dos dispositivos de mesa:

Os players digitais de música estão se libertando, e aos seus usuários, dos computadores, graças a aparelhos capazes de acesso a música naquilo que se tornou conhecido como "a nuvem". Com modelos existentes como o iPhone, da Apple, ou o Ibiza Rhapsody, do Hair Group, bem como o Pre, um celular muito aguardado da Palm, [...] mais e mais audiófilos ganham a capacidade de encontrar, baixar e executar música por sistemas sem fio, sem que precisem conectar seus aparelhos a laptops ou computadores de mesa. [...] "O usuário jamais precisará utilizar o computador de novo, se lhe der na telha", disse Neil Smith, vice-presidente de gestão de negócios da Rhapsody [...] A Rhapsody ainda tem menos de um milhão de usuários, mas existe há mais tempo como um serviço de música por assinatura, que oferece aos usuários de computadores dispostos a pagar 10 dólares ao mês (15 dólares no caso de downloads para players digitais) acesso ilimitado a um catálogo de mais de seis milhões de faixas. (STEVENSON, 2009, doc. não paginado).

A notícia aponta no sentido de tornar antiquados os dispositivos físicos, principalmente aqueles não portáteis (como o computador) e valoriza novos serviços, como a "nuvem", que permite acesso remoto aos programas, serviços e arquivos por qualquer dispositivo conectado à internet, sem necessidade de instalação de programas ou de

\footnotetext{
220 discurso indireto se dá na medida em que novos produtos e/ou serviços foram exaltados - devido a características ditas inovadoras - de maneira a desqualificar e/ou reduzir a vida útil de produtos e serviços que realizavam as mesmas tarefas/funções, embora questões de obsolescência não fossem tratadas de forma literal.
} 
armazenamento de dados. Contudo, esse novo serviço musical possui um custo e diferenciase conforme o dispositivo, criando nova distinção.

\begin{abstract}
"Creio que para os consumidores mais jovens de música, ser dono de uma faixa não importa mais; o que interessa é o acesso a 16 milhões ou 20 milhões de faixas", disse Will Mills, diretor de música e conteúdo da Shazam. [...] Axel Dauchez, o presidente-executivo da Deezer, disse que uma questão importante era a necessidade de ensinar as pessoas que é possível ouvir muita música em seus celulares sem incorrer em pesadas despesas de tráfego de dados. "Quando você chega a esse ponto, ninguém mais precisa ter uma canção gravada em sua máquina", disse. (SANDLE, 2012, doc. não paginado).
\end{abstract}

A mudança de paradigma defendida pelos executivos não é exclusiva da música online, evidentemente. Programas de computador são um entre muitos exemplos possíveis de algo que não se compra mais como um produto físico para ser usado e reusado ao longo dos anos, mas se assina como um serviço. Isto traz ao menos duas vantagens para a empresa: reduz custos (ao dispensar a cadeia produtiva de um produto industrial) e aumenta a periodicidade do pagamento (ao exigir renovações periódicas). Trata-se de questão extensa e complexa, que não cabe desenvolver neste espaço. Nesse sentido, Rifkin (2001) analisa a transferência do negócio baseado em propriedade para um negócio baseado em acesso, alimentando relações a longo prazo com os consumidores:

Na nova era, os mercados estão cedendo lugar às redes, e a noção de propriedade está sendo substituída rapidamente pelo acesso. [...] Isso não significa que a propriedade ira desaparecer no início da Era do Acesso. Ao contrário. A propriedade continuará a existir, mas com uma probabilidade menor de ser trocada em mercados. Em vez disso, os fornecedores detêm a propriedade na nova economia e fazer leasing, alugam ou cobram uma taxa pela admissão, pela assinatura ou pela associação a curto prazo. A troca de bens entre vendedores e compradores - o aspecto mais importante do sistema de mercado moderno - dá lugar ao acesso a curto prazo entre servidores e clientes que operam em rede. (RIFKIN, 2001, p. 4).

Uma notícia também sugeriu a promoção de uma "obsolescência perceptiva", a qual, segundo Goulart (2014), consiste no princípio de fazer com que o consumidor se perceba antiquado ao usar determinado bem ou serviço, sugerindo a aquisição de um item mais novo - a notícia o associa à juventude - visando ao consumo sucessivo de novidades tecnológicas (SANDLE, 2012).

A inovação utiliza um critério ambíguo, já que a obsolescência programada ou perceptiva torna-se, frequentemente, um motor da inovação tecnofetichista (MUTIRÃO DA 
GAMBIARRA, 2010). Há de se considerar, portanto, a adoção discursiva da obsolescência pelo mercado como um fator decisivo na promoção do consumo de novos bens e serviços.

Nesse contexto, os serviços de música online foram caracterizados pelo G1 como híbridos de rede social, sistema de busca e sites de informação musical, constituindo plataformas:

A palavra aqui é segmentação. Serviços como Last.fm e Pandora tentam uma combinação entre colocar na "programação" os artistas da preferência do usuário e o que ele pode vir a gostar. Os dois sites são semelhantes no sentido de que o primeiro passo do internauta é tentar determinar qual é o seu gosto musical, quais são os artistas que agradam. E cada sugestão feita pelos sistemas pode ser acatada ou descartada. A diferença está no fato de que o Pandora trabalha como um "genoma musical". Uma banda ou um cantor já está ligado a outros nesse "mapa genético" e, portanto, uma única indicação do usuário já é suficiente para que o site faça sugestões. (SUZUKI, 2006, doc. não paginado).

Durante o período 2006-2013, o sistema de recomendação (SR) da Last.fm esteve entre os mais populares da internet, situado em primeiro lugar no ranking de número de usuários entre aqueles analisados por Santini (2011) para busca e descoberta de informação. A ferramenta ajuda o usuário a administrar o excesso de informação, recomendando itens que correspondam aos critérios pessoais de relevância e também favorece possíveis descobertas conforme os interesses e gostos pessoais (SANTINI, 2011).

Dessa forma, sistemas de recomendação representam o novo paradigma da classificação, organização, busca e pesquisa em ambientes virtuais por meio da filtragem colaborativa e das preferências dos usuários. A expansão do volume de informação na web tem tornado estas ferramentas atraentes para os usuários, que podem contar com elas diante da "tirania da escolha" (ANDERSON, 2006).

Nesse contexto, deve-se considerar que, segundo a obra The Paradox of Choice, de Barry Schwartz, publicada em 2004, o excesso de escolhas não só gera confusão, mas também é demasiadamente opressivo (ANDERSON, 2006). Sobre o comportamento dos consumidores, Anderson (2006) cita, de Schwartz, a expressão "tirania da escolha" e explica que, com o excesso de oferta, as escolhas não libertam, mas debilitam, e até podem se tornar tiranas. Apesar das consequências negativas da sobrecarga de escolhas, os consumidores querem alternativas, e muitas. Nesse sentido, oferecer abundância de escolhas exige, na mesma medida, recomendações assertivas à altura das preferências individuais. 
Rifkin (2001) aborda a ideia de tecnologias- $R$ para se referir às tecnologias de relacionamento. Para ele, a meta dessas tecnologias seria estabelecer relações comerciais de longo prazo entre o capital e seus clientes, convertendo-se em "conselheiros confiáveis" que instigam e alimentam as "comunidades de interesse". Ferramentas dessa natureza, de intermediação social, sugerida pelos novos negócios de música online, podem se configurar como estratégia de disseminação dos bens culturais e simbólicos em contexto digital, apontando tendências para a organização e orientação do consumo musical segundo técnicas refinadas que utilizam preferências dos usuários.

Essa situação sugere novas questões ao debate sobre diversidade cultural, pois o excesso de experiências mediadas eletronicamente e, de acordo com o gosto de cada um, compromete outras experiências (diversas) que possam ser capazes de produzir empatia e, por que não, tolerância (RIFKIN, 2001; SANTINI; SOUZA; CALVI, 2009). Para Rifkin (2001), a empatia seria o sentimento a partir do qual a confiança social é construída, criando vínculos de intimidade e de civilidade próprios das comunidades. A empatia inclui a compreensão mútua pela qual nos importamos uns com os outros. Por outro lado, quanto mais distante uma pessoa estiver da experiência vivida de outro ser humano, menos provavelmente ela será capaz de sentir empatia.

Para De Marchi (2011), as empresas do entretenimento digital estão se tornando os novos intermediários da indústria fonográfica no entorno digital, reforçando a noção de mediação eletrônica. Dessa forma, como alertam Santini, Souza e Calvi (2009), a indústria da música é setor chave dentro do conjunto das indústrias culturais, irrigando os demais setores por ser componente fundamental de outros produtos culturais, como filmes, televisão, videogames etc. Além disso, a música é um bem simbólico que transcende as barreiras da língua e parece ser o produto cultural com maior potencial de disseminação, principalmente no contexto digital, que permite o acesso a repertórios locais, nacionais e globais e pode servir ao enriquecimento e preservação da diversidade cultural. Para isso, contudo, é fundamental a formulação de políticas públicas que visem à promoção da diversidade cultural também nos ambientes digitais, visto que esse território parece dominado, majoritariamente, pelas megacorporações da iniciativa privada.

Após diversos investimentos mercadológicos, a indústria retomou seu aumento no faturamento, em 2013, após 12 anos de queda. A recuperação foi atribuída ao segmento digital, com destaque para os serviços de assinatura musical Spotify e Deezer (VENDAS..., 2013). Segundo a IFPI (INTERNATIONAL FEDERATION..., 2015), em 2014, as receitas 
globais de música digital já se encontravam em patamar de faturamento próximo ao dos formatos físicos. As receitas digitais, segundo o relatório, representam $46 \%$ de todas as vendas de música no mundo. De acordo com o documento, outros elementos indicam uma indústria em transição: aumento de 46,4\% de pagantes de serviços de assinatura de música online, num total de 41 milhões de usuários no mundo, contrabalanceando uma queda de 8\% na venda de downloads (INTERNATIONAL FEDERATION..., 2015). De acordo com o relatório Digital Music Report de 2014, havia, naquele ano, mais de 450 serviços de música online em mais de 100 países. A América Latina se destacou pelo crescimento de 124\% nos últimos três anos (em relação à data do relatório) quando comparada à média global de 28\%. O relatório do ano seguinte estimou, contudo, que 20\% dos usuários de internet em 2014 ainda acessavam regularmente serviços não licenciados, como as redes de compartilhamento de arquivos P2P (INTERNATIONAL FEDERATION..., 2014, 2015) ${ }^{23}$.

De acordo com os dados da Tabela 1, os usuários brasileiros, por exemplo, permaneceram baixando música pela web entre 2006 e 2014, mesmo que os percentuais não sejam lineares. Por outro lado, a escuta de rádio em tempo real deixa de ser citada na pesquisa anual em 2013, cedendo lugar a "ouvir música online", com 63\%. Embora não se distinga as modalidades - legal/ilegal - do download musical na estatística, a aparição dos serviços de música online como um dos preferidos dos usuários representou uma mudança nos padrões de consumo musical, pela penetração rápida e fulminante dos serviços.

Tabela 1 - Proporção de usuários brasileiros por atividades realizadas na internet (2006-2014)

\begin{tabular}{cccccccccc}
\hline & 2006 & 2007 & 2008 & 2009 & 2010 & 2011 & 2012 & 2013 & 2014 \\
\hline Baixar/fazer download de música & $26 \%$ & $33 \%$ & $32 \%$ & $39 \%$ & $47 \%$ & $51 \%$ & $46 \%$ & $50 \%$ & $51 \%$ \\
Ouvir rádio em tempo real & $27 \%$ & $36 \%$ & $43 \%$ & $40 \%$ & $36 \%$ & $37 \%$ & $29 \%$ & & \\
Ouvir música on-line & $\ldots$ & $\ldots$ & $\ldots$ & $\ldots$ & $\ldots$ & $\ldots$ & $\ldots$ & $63 \%$ & $57 \%$ \\
\hline
\end{tabular}

Fonte: Elaborada pelos autores utilizando dados da pesquisa TIC Domicílios e usuários (2006-2014) do Centro Regional de Estudos para o Desenvolvimento da Sociedade da Informação (2016).

Em relação aos games musicais, desde o lançamento de Guitar Hero, em 2005, estes jogos se tornaram um mercado promissor para a música: “[...] os analistas são unânimes em afirmar que 2007 foi um ano excelente para o setor de videogames, em larga medida devido à ascensão na popularidade de títulos cuja base é a música." (JOGOS..., 2007, doc. não

\footnotetext{
${ }^{23}$ Utilizamos nesta seção alguns dados posteriores a 2014 devido ao notável crescimento de certos serviços, o que sugere um fortalecimento da perspectiva da adaptação.
} 
paginado). 0 interesse pelos games musicais também tem propiciado um incremento nas vendas de guitarras elétricas e o número de pessoas interessadas em tocar instrumentos musicais, de acordo com Herschmann (2010). Segundo o autor, na Inglaterra, 2,5 milhões de jovens começaram a tocar o instrumento musical inspirado em jogos eletrônicos. 0 gênero musical heavy metal também teve destaque entre os games do gênero e, para Herschmann (2010), o jogo tem sido o responsável pelo contato com o estilo musical para muitos adolescentes - cujas bandas fizeram sucesso na adolescência de seus pais - e esse fato poderá trazer consequências importantes sobre a renovação do público consumidor e a criação do gênero musical no futuro.

A Harmonix Music ${ }^{24}$, responsável por jogos como Guitar Hero e Rock Band, foi criada em 1995 por dois estudantes do MIT, Instituto de Tecnologia de Massachusetts (EUA), que se interessaram pela possibilidade de desenvolver jogos musicais: karaokê, dança e instrumentos. Por meio de contratos e parcerias, a empresa fez negócios com Sony (para o jogo Frequency), Microsoft (para a criação do Dance Central) e Apple (para o lançamento do jogo The Beatles: Rock Band), estabelecendo uma cadeia de produção para os games pela existência da segmentação entre produção (plataformas), desenvolvimento (criação) e distribuição (promoção e vendas). Para os jogos Guitar Hero e Rock Band, destacados no G1 (ROCK..., 2008), a produção e distribuição ficaram, respectivamente, com as empresas RedOctane e EA Games (GAMES..., 2008).

Segundo Herschmann (2010), em 2008, pela primeira vez, os games de música superaram a venda dos games esportivos. Os jogos musicais também têm contribuído para a ampliação do consumidor do sexo feminino. Segundo ele, a maior parte do público desses jogos seria composta por mulheres.

Da mesma forma que a música digital vai, paulatinamente, ganhando espaço junto aos formatos físicos, os games parecem seguir a tendência. Em 2015, por exemplo, os downloads de jogos cresceram significativamente no mercado frente à venda em formatos físicos. Analistas atribuem o crescimento à melhoria da velocidade de internet e a maior capacidade em disco, que permitem baixar jogos pesados, evidenciando a significativa marcha rumo ao digital (WINGFIELD, 2015).

\footnotetext{
24 A empresa Harmonix Music foi comprada pela MTV Networks, em setembro de 2006. A MTV Networks faz parte do conglomerado midiático Viacom, que desde 2005 tornou-se CBS Corporation (EUA), quando da divisão da Viacom (HARMONIX..., 2016).
} 


\section{Considerações finais}

Observamos que, majoritariamente, as notícias sobre as disputas judiciais em torno do download reproduziram argumentos em prol da criminalização da prática. A análise das notícias sugere que a criminalização ou a não criminalização, por força de lei, vem sendo atrelada ao interesse econômico das grandes gravadoras. Isto aponta na direção de que o interesse de um segmento específico vem orientando a atuação de diversos setores do Estado, a qual, em geral, foi enquadrada como combate ao crime - portanto, algo correto e desejável.

Este trabalho argumentou que ações simultâneas e paralelas, como diversificação da oferta de serviços e maior vigilantismo na web, foram tomadas ao longo de todo o período investigado, para que os negócios se renovassem e alcançassem uma nova fase, de ascensão.

Houve uma significativa divulgação, pelo G1, de ações antipirataria e de novos bens e serviços tecnológicos. Ela contrasta com raro tratamento de questões sociopolíticas e culturais mais amplas, como direito à cultura no âmbito digital, liberdade de expressão e privacidade, como procuramos demonstrar ao longo do trabalho.

No que se refere à relevância do tema, a internet se mostrou um terreno com enorme potencial cultural por meio de trocas, partilhas e reciprocidades que se encontram ameaçadas por interesses privados, que buscam constantemente controle da rede. Sob um vigilantismo dos "jardins murados", tais interesses colocam em risco direitos como liberdade, segurança e privacidade, recente e arduamente conquistados no Brasil com o Marco Civil da Internet (DANTAS, 2014).

Este novo mercado, caracterizado pela produção de bens imateriais, busca enquadrar as atividades culturais, paulatinamente, como entretenimento pago, na forma de assinaturas, evidenciando um campo de disputas políticas importantes para o atual contexto histórico, no qual tal produção se faz cada vez mais presente na indústria, no comércio e na vida cotidiana, impregnando-se e espraiando-se pelas experiências vividas.

Nesta esteira, a ideia de propriedade, no que se refere à música, tornou-se relativamente sem lugar nos discursos mais recentes (do ponto de vista cronológico) do G1, sendo substituída pela ideia de serviço pago, que garante, em alguma medida, relações de consumo mais duradouras do que o modelo anterior, de produção material. 0 acesso e não a posse parece ter se tornado o centro das relações comerciais e tal modelo pode facilmente ser estendido a inúmeras experiências culturais da atualidade, produzindo o que Rifkin 
(2001) denomina de indústria da experiência - para o autor, a próxima fase do sistema capitalista.

Entre as possíveis contribuições deste trabalho, destacamos os diferentes olhares sob um mesmo fenômeno. A pirataria digital pode ser interpretada pelo viés da criminalização, como também pode ser descrita pelo viés do consumo hedônico sem qualquer fim lucrativo. Observou-se um grande esforço discursivo em propagar o download de música como atividade de lazer sob o signo da venda, reduzindo, no conjunto, outras possibilidades de acesso, troca e partilha.

Consideramos importante encontrar brechas nesta tendência de apropriação dos afetos, em que variados tipos de sociabilidade ou relação social se transformam, em parte, em potência comercial na rede por meio de plataformas proprietárias, aplicativos e estratégias de marketing. Debater e analisar a cobertura midiática sobre os distintos usos da rede nos parece um passo nesta direção, daí o esforço deste artigo.

\section{Financiamento}

A pesquisa de doutorado, da qual este trabalho apresenta alguns resultados, contou com financiamento da Coordenação de Aperfeiçoamento de Pessoal de Nível Superior (CAPES), na modalidade CAPES/REUNI.

\section{Referências}

ADORNO, Theodor W.; HORKHEIMER, Max. A Indústria cultural: o esclarecimento como mistificação das massas. In: ADORNO, Theodor W.; HORKHEIMER, Max. Dialética do esclarecimento. 2. ed. Rio de Janeiro: Jorge Zahar, 1985. p. 113-156.

ALEXA. Traffic Statistics. How popular is globo.com? 2018. Disponível em: <https://www.alexa.com/siteinfo/globo.com>. Acesso em: 29 jan. 2018.

ANDERSON, Chris. A cauda longa: do mercado de massa ao mercado de nicho. Rio de Janeiro: Campus, 2006.

AVÓ é multada em US\$650 por baixar 3.000 canções na internet. G1, Rio de Janeiro, 9 mar. 2007.

BRASIL. Câmara dos Deputados. Comissão Parlamentar de Inquérito da Pirataria. Relatório [CPI da pirataria]. Relator Dep. Josias Quintal. Brasília, DF, 2004. 
BRASIL. Lei no 9.610, de 19 de fevereiro de 1998. Altera, atualiza e consolida a legislação sobre direitos autorais e dá outras providências. Diário Oficial [da] União, Brasília, 20 fev. 1998.

BRASIL. Lei no 10.406, de 10 de janeiro de 2002. Institui o Código Civil. Diário Oficial [da] União, Brasília, 11 jan. 2002.

BRASIL. Lei no 10.695, de 1 de julho de 2003. Altera e acresce parágrafo ao art. 184 e dá nova redação ao art. 186 do Decreto-Lei no 2.848 [...]. Diário Oficial [da] União, Brasília, 2 jul. 2003.

BRASIL. Ministério da Justiça e Segurança Pública. Combate à pirataria. [Brasília, 2017].

BRITTOS, Valério Cruz; BOLAÑO, César Ricardo Siqueira (Org.). Rede Globo: 40 anos de poder e hegemonia. São Paulo: Paulus, 2005.

CANTOR do Radiohead vai lançar duas músicas inéditas. G1, São Paulo, 3 set. 2009.

CARPANEZ, Juliana. Operação da PF contra pirataria prende 7 pessoas em 4 Estados. G1, São Paulo, 1 jul. 2008.

CARTA CAPITAL. Observatório da Privacidade e Vigilância. [2016].

CENTRO REGIONAL DE ESTUDOS PARA O DESENVOLVIMENTO DA SOCIEDADE DA INFORMAÇÃO. Indicadores sobre o uso das TIC no Brasil (2006 a 2014). [2016].

COMITÊ GESTOR DA INTERNET NO BRASIL. Pesquisa sobre o uso das tecnologias da informação e da comunicação no Brasil: TIC domicílios e usuários 2011. São Paulo, 2011.

CRUZ, Leonardo Ribeiro da. Internet e direito autoral: o ciberespaço e as mudanças na distribuição cultural. 2008. 207 f. Dissertação (Mestrado em Ciências Sociais) - Faculdade de Filosofia e Ciências, Universidade Estadual Paulista, Marília, 2008.

DANTAS, Marcos. Mais-valia 2.0: produção e apropriação de valor nas redes do capital.

Revista Eptic, São Cristóvão, v. 16, n. 2, p. 89-112, maio/ago. 2014.

DE MARCHI, Leonardo Gabriel. Transformações estruturais na indústria fonográfica no Brasil (1999-2009). 2011. Tese (Doutorado em Comunicação e Cultura) - Escola de Comunicação, Universidade Federal do Rio de Janeiro, 2011.

DOWNLOAD dá multa de R\$400 mil nos EUA. G1, Rio de Janeiro, 5 out. 2007.

EM 2005, 1,1 bilhão de downloads ilegais foram feitos no Brasil. G1, Rio de Janeiro, 17 out. 2006.

EMI se une a site de buscas chinês após perder ação na Justiça. G1, Rio de Janeiro, 17 jan. 2007. 
ESTUDANTE é processado por gravadoras por fazer download ilegal de músicas. G1, Rio de Janeiro, 30 jul. 2009.

EUA: mulher é condenada a pagar US\$1,5 mi por baixar música. G1, Rio de Janeiro, 4 nov. 2010.

EUA obrigam estudante a destruir músicas baixadas ilegalmente. G1, Rio de Janeiro, 8 dez. 2009.

GAMES se transformam em canal de distribuição para indústria musical. G1, Rio de Janeiro, 21 dez. 2008.

GOOGLE lança serviço de download gratuito de música para China. G1, Rio de Janeiro, 30 mar. 2009.

G00GLE lança serviço de download gratuito na China. G1, Rio de Janeiro, 7 ago. 2008a.

GOOGLE planeja acordo para oferecer download grátis na China. G1, Rio de Janeiro, 6 fev. 2008b.

GOULART, Fábio. Alienação e reificação na indústria cultural e internet. 2014.

Dissertação (Mestrado em Filosofia) - Faculdade de Filosofia e Ciências Humanas, Pontifícia Universidade Católica do Rio Grande do Sul, Porto Alegre, 2014.

GOVERNO dos EUA fecha Megaupload e prende seu fundador. G1, Rio de Janeiro, 19 jan. 2012.

GRAVADORAS obtêm decisão inédita contra troca de arquivos no Brasil. G1, Rio de Janeiro, 18 set. 2009.

HARMONIX Music Systems. In: Wikipédia, a enciclopédia livre. [S.l.]: Wikimedia Foundation, 2016.

HERSCHMANN, Micael. Indústria da música em transição. São Paulo: Estação das Letras, 2010.

HOLTON, Kate. Indústria da música precisa abraçar internet. G1, São Paulo, 19 jan. 2009.

INSTITUTO DE PESQUISA ECONÔMICA APLICADA. Download de músicas e filmes no

Brasil: um perfil dos piratas online. [Brasília, DF], 2012. (Comunicados do Ipea, n. 147).

INTERNATIONAL FEDERATION OF THE PHONOGRAPHIC INDUSTRY. Digital music report 2014. 2014.

INTERNATIONAL FEDERATION OF THE PHONOGRAPHIC INDUSTRY. Digital music report 2015. 2015.

INTERNATIONAL FEDERATION OF THE PHONOGRAPHIC INDUSTRY. Members. 2018. 
INTERNAUTA é detido por permitir download de inéditas do Guns N "Roses. G1, Rio de Janeiro, 27 ago. 2008.

JOGOS musicais turbinam indústria dos videogames. G1, Rio de Janeiro, 17 dez. 2007.

JUIZ fecha serviço de compartilhamento de música Limewire. G1, Rio de Janeiro, 26 out. 2010.

JUSTIÇA sueca condena diretores do site Pirate Bay à prisão. G1, Rio de Janeiro, 17 abr. 2009.

KIKKO, Vanessa Okada. 0 futuro da indústria da música no Brasil. 2012. Dissertação (Mestrado em Administração) - Escola de Administração de Empresas de São Paulo, Fundação Getúlio Vargas, São Paulo, 2012.

LEMOS, Ronaldo. Direito, tecnologia e cultura. Rio de Janeiro: FGV, 2005.

LIMA, Tatiana Rodrigues. 0 balanço do bit: mediações da música na era digital. 2013. Tese (Doutorado em Comunicação e Cultura Contemporâneas) - Faculdade de Comunicação, Universidade Federal da Bahia, 2013.

LOUREIRO, Cláudia. Campanha internacional contra a pirataria começa no Rio. G1, Rio de Janeiro, 17 out. 2006.

MACHADO, Jorge. Desconstruindo propriedade intelectual. São Paulo: Universidade de São Paulo; Bauru: Canal 6, 2010.

MORAES, Cândida Maria Nobre de Almeida. Pirataria no ciberespaço: como a lógica de reprodutibilidade industrial disponibilizada pelas novas tecnologias afeta a própria indústria. João Pessoa: Marca de Fantasia, 2010.

MUTIRÃO DA GAMBIARRA. Gambiologia. [S.l]: Metalivros, 2010.

ORGANIZAÇÕES GLOBO. Princípios editoriais das Organizações Globo. Rio de Janeiro, 2011.

PAGANOTTI, Ivan. Pressão virtual e regulamentação digital brasileira: análise comparativa entre o Marco Civil e a Lei Azeredo. In: SOUSA, Helena et al. Media policy and regulation: activating voices, illuminating silences. Braga: Universidade do Minho, 2013. p. 124-142.

PATEL, Raj. 0 valor de nada: por que tudo custa mais caro do que pensamos. Rio de Janeiro: Zahar, 2010.

PF REALIZA operação para combater pirataria na internet. G1, São Paulo, 1 jul. 2008.

PRO-MÚSICA BRASIL. Produtores Fonográficos Associados. Produtores - Pro-Música. c2018. 
RIFKIN, Jeremy. A era do acesso: a transição de mercados convencionais para networks e o nascimento de uma nova economia. São Paulo: Makron Books, 2001.

'ROCK band' e 'Guitar hero' impulsionam a venda de música digital. G1, Rio de Janeiro, 21 jan. 2008.

SANDLE, Paul. Smartphones e Facebook ajudam música online a amadurecer. G1, Rio de Janeiro, 18 jun. 2012.

SANTINI, Rose Marie. A arte do avesso: a função da denegação econômica no mercado artístico e as novas formas de recomendação e mediação cultural na internet. Revista Eptic, São Cristóvão, v. 13, n. 2, p. 1-22, maio/ago. 2011.

SANTINI, Rose Marie; SOUZA, Rosali Fernandez de; CALVI, Juan C. A organização do consumo de música na internet através da classificação do gosto musical: estudo de caso do sistema de recomendação Last Fm. In: ROMERO, Nuria Lloret (Coord.). Nuevas perspectivas para la difusión y organización del conocimiento: actas del congreso. [Valencia]: Universidad Politécnica de Valencia, 2009. p. 289-304.

SELAIMEN, Graciela Baroni. Provedores de acesso à internet, dados pessoais e privacidade: para que regulação? In: BARINDELLI, Florencia; GREGORIO, Carlos G. (Org.). Datos personales y libertad de expresión en las redes sociales digitales. Buenos Aires: Adhoc, 2010. p. 221- 261.

SITE vai oferecer mais de 25 milhões de músicas gratuitas. G1, Rio de Janeiro, 28 jan. 2008.

SOARES, Elisianne Campos de Melo. Regulação do ciberespaço, controlo dos fluxos informacionais e direitos de autor: os casos de Portugal e do Brasil. 2012. Dissertação (Mestrado em Cultura e Comunicação) - Faculdade de Letras da Universidade de Lisboa, 2012.

SOUZA, Carlos Henrique Medeiros et al. Impresso x online: a credibilidade do discurso jornalístico em pauta. In: CONGRESSO INTERNACIONAL INTERDISCIPLINAR EM SOCIAIS E HUMANIDADES, 2., 2013, Belo Horizonte. Anais... Belo Horizonte, 2013.

STEVENSON, Reed. Aparelhos de música encontram vida além do computador. G1, Rio de Janeiro, 29 abr. 2009.

SUZUKI, Shin Oliva. Saiba onde ouvir e baixar música de graça na rede dentro da lei. G1, São Paulo, 18 dez. 2006.

THOMPSON, John B. Ideologia e cultura moderna: teoria social crítica na era dos meios de comunicação de massa. Petrópolis: Vozes, 1995.

VELEDA, Rodrigo. Listagem atualizada de PLs na Câmara sobre o controle da Internet. Blog Não Sou um Número, 19 dez. 2009.

VENDAS de música têm em 2012 primeira alta desde 1999. G1, Rio de Janeiro, 26 fev. 2013. 
VIANA, Juliana de Alencar. Ascensão e queda: o download de música na internet nos discursos do Portal G1 (2006 - 2013). 2016. Tese (Doutorado em Estudos do Lazer) Universidade Federal de Minas Gerais, Belo Horizonte, 2016.

VIDAL, Gabriel Rigoldi. Privacidade e internet. Revista Eletrônica de Direito/UNESP, Franca, n. 1, p. 1-11, 2010.

WACHOWICZ, Marcos (Org.). Por que mudar a Lei de Direito Autoral: estudos e pareceres. Florianópolis: Fundação Boiteux, 2011.

WACHOWICZ, Marcos; SANTOS, Manoel J. Pereira dos (Org.). Estudos de direito de autor: a revisão da Lei de Direitos Autorais. Florianópolis: Fundação Boiteux, 2010.

WINGFIELD, Nick. Mercado de games tem virada digital em 2015. Estadão, São Paulo, 27 dez. 2015 .

WOOD, Ellen Meiksins. A origem do capitalismo. Rio de Janeiro: Jorge Zahar, 2001.

\title{
Repression, adaptation, reinvention: downloading music as leisure and business on the internet (2006-2013)
}

\begin{abstract}
This paper presents some findings of a PhD thesis on how the music download was represented in the G1 news portal between 2006 and 2013. The research examined 713 stories with the assistance of software Nvivo10. When examining the data collected, we observed that there was a moment of repression and persecution of users, as well as closing out of sites and networks of music-sharing due to violation of copyright laws. Later there was an adaptation of the industry through the release of free digital music in exchange for audience-based advertising revenue. Finally, there was a reinvention of music as a business by the music industry, expanding and diversifying it through sales of subscription to online music services and music games.
\end{abstract}

\section{Keywords}

Music download. G1. News stories. Media. Criminalization.

Recebido em 28/05/2017

Aceito em 09/10/2017 